\title{
Seminario «Modelos de gestión del agua en ciudades y comunidades de los Andes»
}

La Paz, 5-8 de noviembre de 2007

\section{Franck Poupeau}

\section{(2) OpenEdition}

Journals

Edición electrónica

URL: http://journals.openedition.org/bifea/3769

DOI: 10.4000/bifea.3769

ISSN: 2076-5827

\section{Editor}

Institut Français d'Études Andines

\section{Edición impresa}

Fecha de publicación: 1 diciembre 2007

Paginación: 466-467

ISSN: 0303-7495

\section{Referencia electrónica}

Franck Poupeau, «Seminario «Modelos de gestión del agua en ciudades y comunidades de los Andes» », Bulletin de l'Institut français d'études andines [En línea], 36 (3) | 2007, Publicado el 01 junio 2008, consultado el 01 diciembre 2020. URL : http://journals.openedition.org/bifea/3769 ; DOI : https://doi.org/10.4000/bifea.3769

Les contenus du Bulletin de l'Institut français d'études andines sont mis à disposition selon les termes de la licence Creative Commons Attribution - Pas d'Utilisation Commerciale - Pas de Modification 4.0 International. 


\section{SEMINARIO «MODELOS DE GESTIÓN DEL AGUA EN CIUDADES Y COMUNIDADES DE LOS ANDES»}

La Paz, 5-8 de noviembre de 2007

El seminario «Modelos de gestión del agua en ciudades y comunidades de los Andes» se ha desarrollado en el Museo Nacional de Etnografía y Folklore de La Paz, Bolivia, del 5 al 8 de noviembre de 2007 y ha reunido a más de 30 investigadores bolivianos, franceses, italianos, colombianos, noruegos y estadounidenses en el transcurso de tres conferencias magistrales y de seis talleres distribuidos a lo largo de estos días. Más de 300 personas se inscribieron para asistir al evento, pero la falta de expedientes previstos durante las dos últimas jornadas reduce probablemente esta cifra.

El seminario fue inaugurado la tarde del lunes 5 de noviembre por Ramiro Molina director del MUSEF, Godofredo Sandoval, director del PIEB, Alain Fouquet Embajador de Francia en Bolivia, Franck Poupeau, representante del IFEA en Bolivia, antes que Bernard Barraqué, director de investigaciones del CNRS (Centro Nacional de Investigación Científica de Francia) de apertura a la parte propiamente científica de estas jornadas con una conferencia sobre «el derecho al agua y el derecho del agua». Él hizo en particular una distinción entre el derecho al recurso natural en condiciones rurales y la necesidad de asegurar el servicio de distribución en condiciones urbanas, lo que limita la idea de un derecho ilimitado al agua. El comentarista de esta conferencia fue el Vice-Presidente de la República de Bolivia, Alvaro García Linera, quien en su condición de sociólogo, disertó sobre las relaciones ente el Estado boliviano y las comunidades rurales o citadinas en materia de gestión del recurso.

Las jornadas siguientes reunieron a los investigadores de los diferentes países en torno a las temáticas escogidas: en primer lugar, se hizo un inventario de la gestión del servicio de agua en los espacios urbanos en expansión en el que se comparó los casos boliviano, colombiano y peruano; se dedicó una sesión más específica a los conflictos ligados a los derechos de acceso al recurso en diversos sectores urbanos y rurales del territorio boliviano, y en las zonas fronterizas con Brasil, Perú o Chile. Esa misma noche, ante una nutrida concurrencia, Joël Ruet dictó una conferencia sobre los problemas que unen al desarrollo con el medio ambiente, a partir del caso de la India: haciendo hincapié sobre la necesidad de renovar a su tiempo las infraestructuras, criticó así la visión maltusiana que predomina en el sector de 
los servicios, para mostrar cómo las periferias populares en expansión, como El Alto, podían por el contrario constituir una suerte para las ciudades de las clases medias.

La jornada siguiente estuvo más dedicada a los problemas de acceso al recurso en las comunidades rurales, y en particular a las penurias de las mujeres que tienen a su cargo el espacio doméstico. Al mediodía, Bernard Barraqué disertó ante 80 personas en el departamento de estudios consagrado al desarrollo de la Universidad Pública de El Alto, bajo la responsabilidad de la Vice-Presidencia. Por la tarde se tuvo la oportunidad regresar sobre la guerra del agua en Cochabamba examinándola en dos niveles: primero se analizó los factores del fracaso de la empresa municipal SEMAPA, que sucedió a la empresa privada Aguas del Tunari; y después se retornó sobre las dificultades actuales de las organizaciones sociales para ejercer un control social sobre las empresas «re-municipalizadas». Por la noche, Pierre Roussel, inspector general del Ministerio del Medio Ambiente francés, dio una conferencia sobre las políticas del agua a nivel mundial y sobre el modelo francés.

La última jornada se abrió con un taller consagrado a la elaboración de modelos de gestión del servicio de agua, tomando en cuenta perspectivas jurídicas, económicas y sociológicas, con el objeto de preparar la discusión de la tarde, dedicada al mismo tema, pero haciendo dialogar actores políticos e investigadores franceses. Estuvieron presentes el gerente de la empresa ESPAS, que distribuye el agua en los municipios de La Paz y El Alto, un representante de la Superintendencia de Servicios Básicos, un representante de la Coordinadora de Defensa del Agua y la Vida de Cochabamba, así como los tres conferencistas franceses. Así, se llevó a cabo un debate de más de 3 horas sobre las políticas públicas destinadas a favorecer la universalización del acceso al recurso, sobre la durabilidad de los modelos de gestión implementados y sobre las dificultades de la participación social. Actuó como moderador Carlos Crespo, un reconocido investigador boliviano, quien permitió que la discusión se mantenga dentro del marco de los argumentos y profundice las perspectivas comparativas abiertas en el transcurso de estas tres jornadas de conferencias. 